\title{
La dependència de l'energia fòssil i el nostre futur energètic
}

\author{
Mario Giampietro \\ Professor de Recerca ICREA, Institut de Ciència i Tecnologia Ambientals (ICTA-UAB)
}

El consum d'energia fòssil és a la base del funcionament de la nostra societat. Tanmateix, molts científics es mostren escèptics sobre la possibilitat de conservar aquest estil de vida en un context que necessàriament haurà de reduir dràsticament el ritme actual de consum d'energia fòssil. En un futur més proper del que sembla, haurà de canviar el sistema d'alimentació, els transports, la producció de béns i la manera de viure de les persones.

Paraules clau: energia, consum, el pic del petroli, alternatives energètiques, eficiència, paradoxa de Jevons

La nostra dependència de l'energia fòssil genera molts interrogants sobre el futur energètic de la nostra societat. Centrarem l'atenció en alguns dels punts clau de la polèmica.

\section{Intoxicació ideològica en el debat sobre la sostenibilitat}

En un moment clau de la pel-lícula Matrix, el protagonista ha de triar entre dues píndoles (fig. 1): la blava el farà viure en un món on tot va bé, mentre que la vermella li mostrarà la veritat.

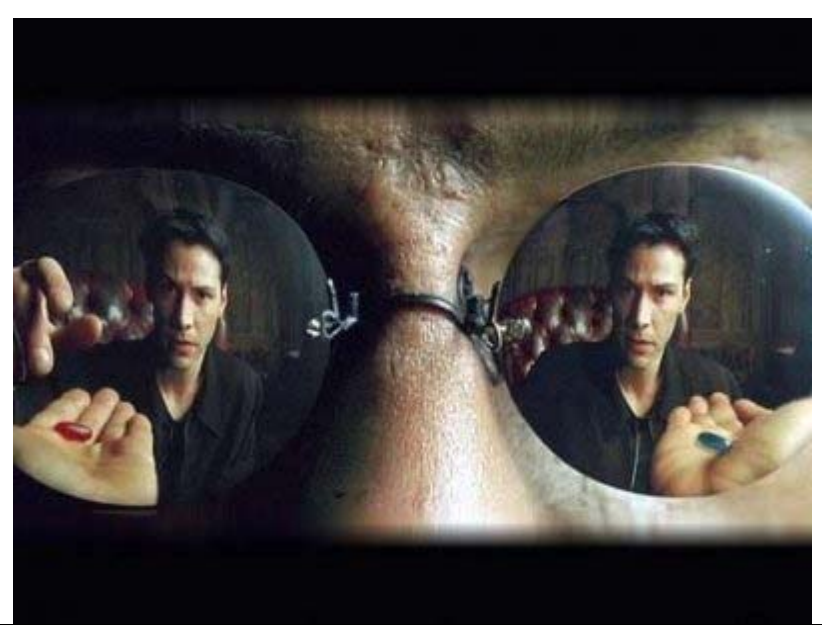

Figura 1. Escena de Matrix. El hacker Neo ha d'escollir entre dues píndoles.
En el debat energètic també podem optar per enganyar-nos pensant que tot seguirà igual... o bé encarar el problema, analitzar les dades que tenim, preveure raonablement el que ens espera per aquest camí i decidir les opcions més convenients.

I les dades són clares (fig. 2): el creixement del consum d'energia és superior al ritme de creixement de la població mundial.

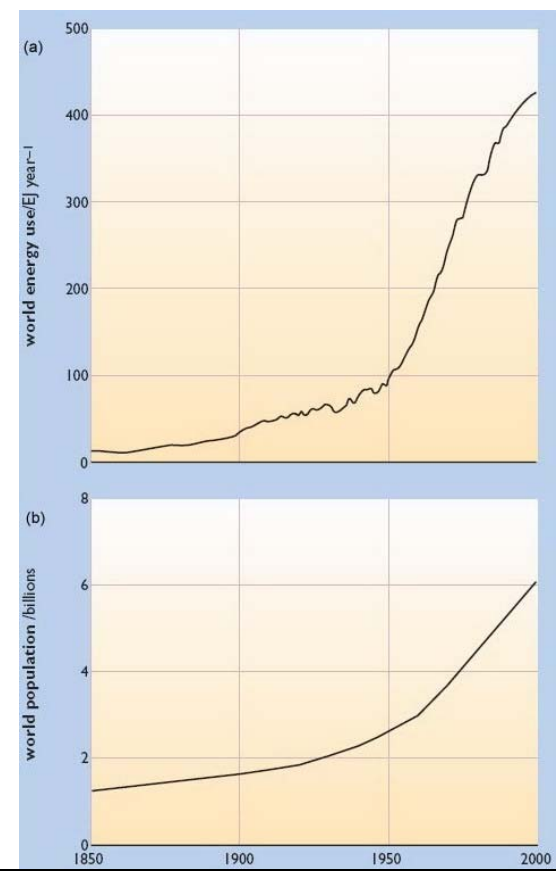

Figura 2. A dalt, evolució del consum mundial d'energia. A sota, creixement de la població (Unicef). 
Ni la població humana ni els recursos poden continuar creixent com ho estan fent actualment en un planeta finit que ja dóna signes d'esgotament.

Un important informe per al Club de Roma, del ja llunyà 1972, "Els límits del creixement", ja preveia problemes en les primeres dècades del tercer mil.lenni... La revisió i actualització del document, feta per Ugo Bardi, "The limits to growth revisited" (2011), confirma que les previsions sobre els problemes amb matèries primeres eren força precisos.

Ens hem acostumat a valorar la prosperitat d'una economia mitjançant la taxa de creixement econòmic: com més creix, millor. Però això només és perquè som sota els efectes de la píndola blava! En el món real, més no sempre vol dir millor.

L'economista Kenneth Boulding deia que "qui creu en un creixement exponencial indefinit en un món finit és un boig... o un economista". El creixement indefinit no és una idea ni realista ni desitjable. Més aviat és un simple conte de fades: pot ser agradable de sentir, però ens equivocaríem si ens el creguéssim.

Si ens deixem de contes ens adonarem que créixer genera problemes i la producció de petroli la nostra font energètica fonamental- ha arribat a un límit i ja no pot créixer més. Les dades (fig. 3) ens diuen amb claredat que ha tocat sostre.

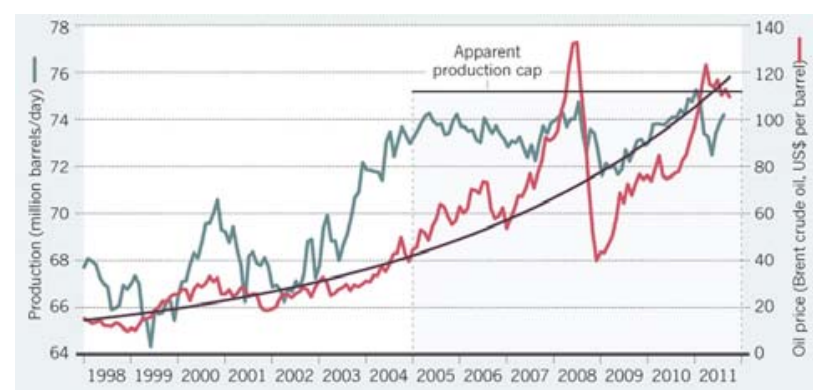

Figura 3. La línia blava representa la producció mundial de petroli de 1998 al 2011, que sembla haver tocat sostre des del 2005. Les línies vermelles mostren l'evolució del seu preu. (Murray i King, Nature 2012)

Com es veu a la gràfica, mentre la producció mundial de petroli s'estabilitzava a partir del 2005, el preu del barril pujava de forma molt accentuada. L'elevat preu de l'energia va generar la crisi, que va reduir la demanda. Des de llavors tenim una contínua oscil-lació generada pel següent mecanisme: preus alts $\rightarrow$ crisi econòmica $\rightarrow$ la demanda baixa $\rightarrow$ els preus baixen $\rightarrow$ l'economia es recupera $\rightarrow$ l'augment de la demanda implica preus més alts $\rightarrow$ els preus elevats reinicien el cicle

L'arribada al sostre de la producció mundial de petroli ha impulsat l'augment del seu preu, ja que si abans l'oferta era elàstica perquè es podia adaptar a la demanda -produir més- ara ha esdevingut inelàstica (fig. 4).

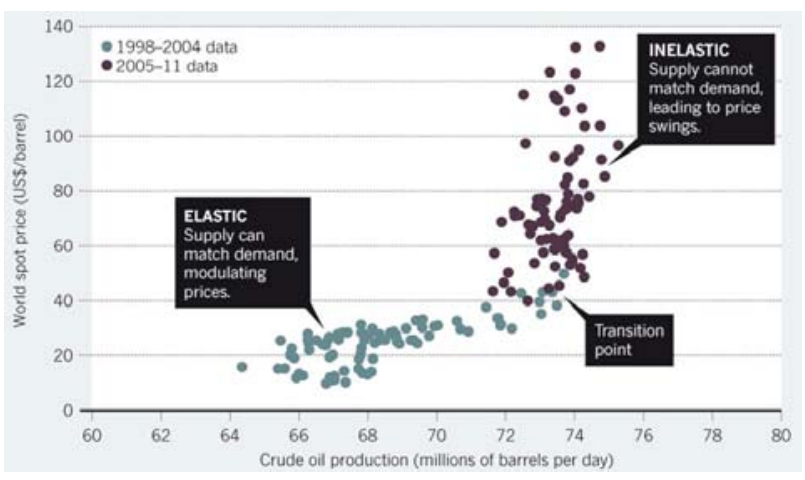

Figura 4. El preu del petroli en funció de la producció. En color blau, dades de 1998 al 2004 i, en morat, de 2005 al 2011. (Murray i King, Nature 2012)

L'economia del petroli pot haver traspassat un llindar (transition point a la gràfica anterior). Vist això, ens preguntem quines en poden ser les conseqüències en el futur.

\section{Els problemes futurs: les conseqüències del "peak oil"}

De vegades s'ha confós l'arribada al pic del petroli amb l'esgotament dels recursos. Arribar al "peak oil" marca el màxim en el ritme d'extracció del petroli, encara que en restin importants quantitats en reserves. És cert que els jaciments més rics probablement ja s'han descobert i que hem estat extraient el petroli més assequible i de millor qualitat. Tot plegat significa que hem de donar per acabada l'era de petroli barat, que ha transformat tant el món, i que a partir d'ara l'haurem de pagar a un preu força més alt.

És fàcil entendre que l'acabament de l'era del petroli barat tindrà conseqüències importants: 
- Primer de tot, suposa un cop molt dur per a les nostres economies i per a la nostra civilització, basada, durant més d'un segle, en l'oferta de petroli barat. Pensem, per exemple, què pot significar per a la indústria de l'automòbil, per al transport per carretera, per mar i per aire. Podrem mantenir el nostre cotxe? Podrem seguir viatjant en vols "low cost"?

- Els baixos preus del petroli han suposat un creixement enorme de la riquesa, una urbanització massiva (amb bombolles immobiliàries...) fins a acostumar-nos a un creixement econòmic continuat com a sinònim de prosperitat. Una altra idea que haurem de revisar.

- Finalment, l'economia s'ha instal.lat en el miratge que es poden fer bons negocis especulant $i$ canviant de lloc els diners en el moment oportú. Desafortunadament, l'economia purament financera en conjunt no crea riquesa si la base biofísica de l'economia no creix. En un joc de suma zero si algú s'hi enriqueix és a costa d'altres que hi surten perdent: un sistema semblant a les estafes "piramidals" o els "esquemes Ponzi". El resultat és que s'ha enverinat l'economia pel fet que els mercats financers s'han habituat a operar a una taxa de retorn de la inversió superior al rendiment que es pot aconseguir amb les tradicionals activitats econòmiques biofísiques!

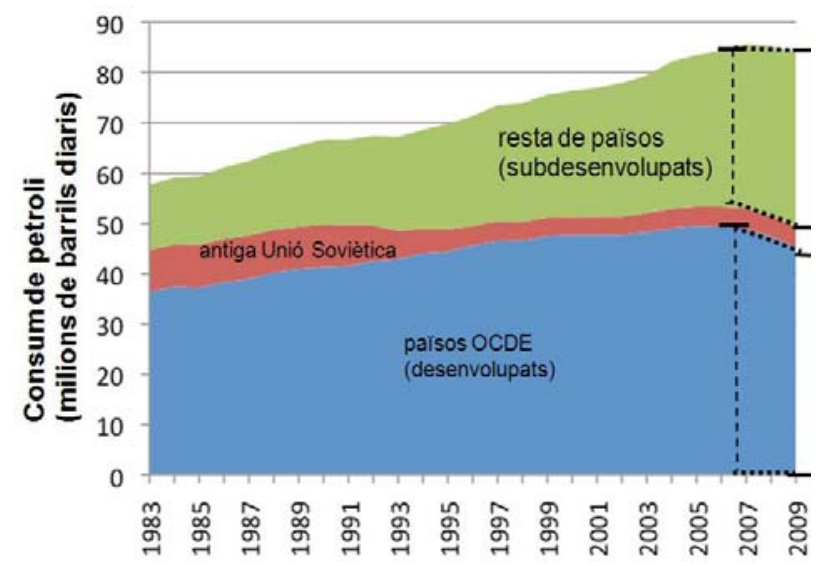

Figura 5. Gràfica de consum de petroli, comparant països de l'OCDE i la resta (Giampietro et al. 2011. Font: BP Statistical Review of World Energy 2010).

Com que el tall de pastís haurà de ser menor per a tothom, seria just que els que més n'han gastat, siguin els que més en redueixin el consum (fig. $6)$.
La narració bàsica del progrés parla d'un pastís en contínua expansió. Aquest pastís va ser sostingut pel consum de petroli, que es repartia només entre els països més rics. Ara, no només el consum de petroli ja ha parat de créixer, sinó que s'ha de repartir entre més: cada vegada més països en demanen més (fig. 5).

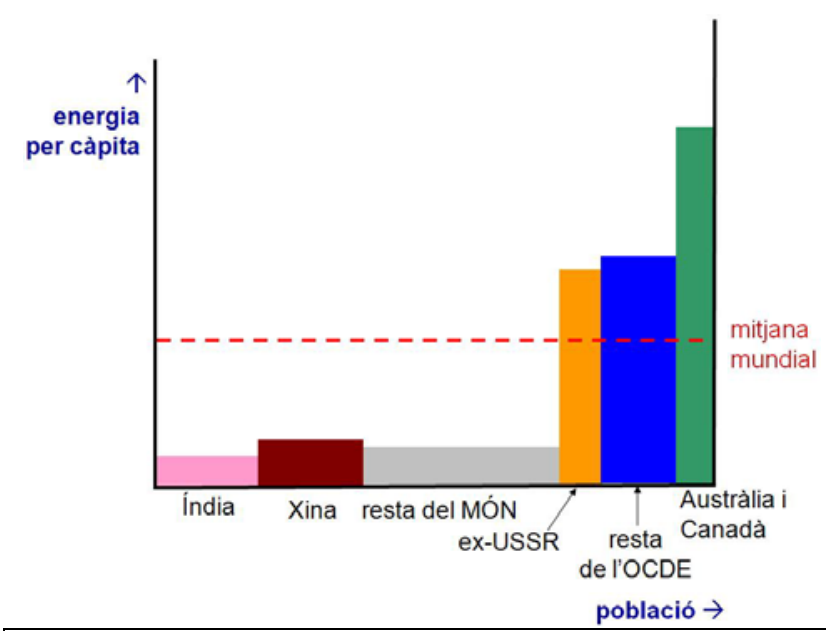

Figura 6. Gràfica de consum de petroli per càpita comparant països en relació a la població (Giampietro et al. 2011)

Però el que és previsible és que no succeeixi això, sinó que el creixement de la demanda creï més tensions.

Per exemple, si el protocol de Kyoto pretenia disminuir les emissions de diòxid de carboni, el resultat real és que, tot i les negociacions, els consums d'energia fòssil han augmentat més que mai (fig. 7), sobretot a causa de la globalització.

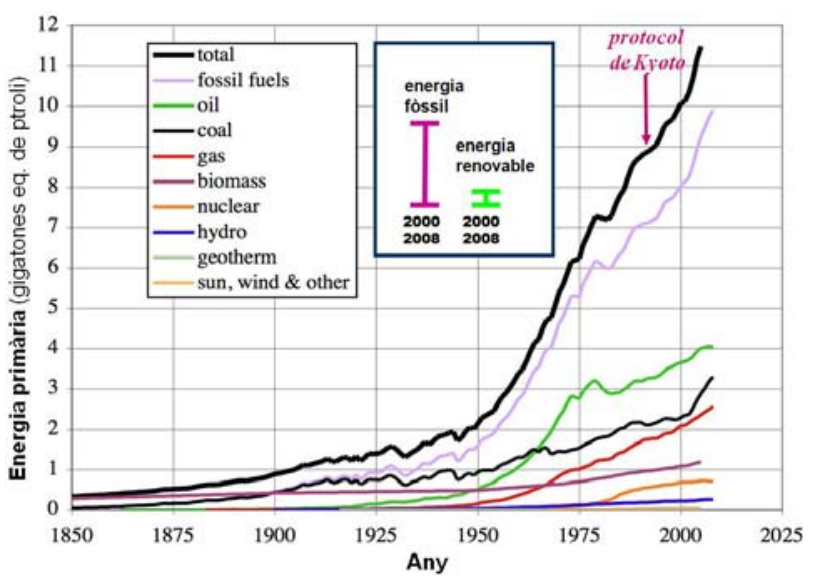

Figura 7. Consum mundial d'energia al llarg dels anys. -Dades: J. Laherrere (Giampietro et al. 2011) 


\section{La dificultat de predir escenaris futurs: la paradoxa de Jevons}

El 1865 William Stanley Jevons va observar que les innovacions en les màquines de vapor mogudes per carbó milloraven la seva eficàcia en relació a sistemes anteriors, però aquesta millora generava un augment i no una reducció del consum de carbó! De fet, sembla raonable esperar que més eficiència fes disminuir el consum de carbó; però de fet, a la llarga, s'incrementava ja que s'utilitzava en més ocasions (paradoxa de Jevons o efecte rebot). Així, davant del problema energètic cal tenir en compte que com més augmenti l'eficiència possiblement se n'acabi consumint més.

En aquest punt voldria fer una pregunta que pot resultar xocant al lector, per fer-lo pensar: qui és més feliç al cap dels anys, el que li toca la grossa a la loteria o el que es queda paraplègic? La resposta pot sembla òbvia: més val un cop de sort que un de desgràcia. Doncs bé, una recerca científica que s'ha fet mostra que a la llarga no hi ha diferència entre l'un i l'altre. Els humans a la llarga acabem acostumant-nos a allò que tenim i vivim.

Això ve a compte perquè ara, després de dècades de creixement econòmic, ens hi hem acostumat. Però de debò som ara més feliços en conjunt que, per exemple, fa cinquanta anys? Disposem de més béns, potser som més rics, però amb la mà al cor difícilment podem afirmar que som més feliços.

La reducció en el consum d'energia, a la llarga, no ens ha de fer més infeliços, sinó ben al contrari. Tot depèn de si sabem trobar, tots plegats, formes més raonables de viure i menys costoses.

\section{Tenim bones alternatives?}

Per aconseguir-ho hem de mirar quines alternatives tenim a la producció energètica actual (es pot trobar una discussió més detallada d'aquest tema a http://elnostrefuturenergetic.cat/).

\section{L'energia nuclear}

Si s'ha desenvolupat ha estat sempre més per motivacions militars que energètiques. Però des dels anys 70 gairebé que no es construeixen reactors. L'ús civil de l'energia nuclear mai no ha estat econòmicament rendible considerant els alts riscos en cas d'accident i de les inversions a llarg termini que requereix. Al cap i a la fi, concentra un munt de problemes quan simplement es tracta d'escalfar aigua, cosa que podem fer molt millor amb altres mètodes. Si l'incident de Txèrnobil ens deixà glaçats, el recent a Fukushima encara ha refredat més l'interès per aquesta font d'energia.

\section{El vent}

Els molins de vent són el sistema sostenible que més ha funcionat, però amb alguns problemes: que no sempre hi ha vent, generant discontinuïtats en el subministrament que provoquen problemes d'estabilitat a la xarxa elèctrica del país. Aquesta és una alternativa prometedora, però només podem esperar que ens permeti cobrir una part dels nostres consums d'energia (per exemple, un $20 \%$ de l'electricitat).

\section{Biocombustibles}

Produir petroli a partir dels aliments és molt mala idea. La població ha anat augmentant perquè hem pogut produir aliment utilitzant el petroli com a combustible i per fabricar fertilitzants. És de bojos pretendre ara utilitzar el menjar per fer combustible. En emissions de $\mathrm{CO}_{2}$ empitjoraria la situació a causa de l'efecte del canvi en l'ús del sòl, i produiria encariments irresponsables en el preu dels aliments. La segona generació de biocombustibles encara és lluny de prometre una font abundant i fiable d'energia.

\section{Biomassa}

Per a determinades aplicacions la biomassa és una bona alternativa: per a la generació de calor de procés, per a la producció de electricitat, recuperació de residus. Un camp a explorar. Però tot i així no hem d'esperar massa d'aquesta font.

\section{Fotovoltaica}

És l'eterna promesa, però fins ara no ha acabat de madurar. En imaginar una aplicació a gran escala hi ha problemes amb els materials. Tot i que s'hi han invertit molts diners, no acaba de ser prou productiva.

\section{Hidroelèctrica}

Als països rics ja no dóna per més, però encara hi ha països amb potencial. Pot tenir un impacte social molt fort i també en el territori. És imprescindible disposar d'un bon cabal d'aigua i d'una orografia adequada.

\section{Hidrogen}

No es tracta d'una font energètica, sinó d'un "carrier", un portador d'energia produïda per altres mitjans.

En aquesta ullada a les alternatives energètiques és obligatori comentar les possibilitats del cotxe elèctric. Fins ara la tecnologia del cotxe elèctric ha mostrat limitacions, com la seva limitada autonomia, l'excessiu pes de les bateries, i que en un ús a gran escala podria crear problemes a la xarxa 
elèctrica amb càrregues difícils de predir en l'espai $\mathrm{i}$ el temps. Podria anar bé alimentar-lo amb piles de combustible, que consumeixen hidrogen i alliberen vapor d'aigua, inofensiu per a l'ambient, però la tecnologia encara no és satisfactòria.

En termes generals podem dir que una disminució de l'ús del petroli sense un canvi en el nostre patró de consum d'energia hauria d'anar acompanyada de la introducció massiva de noves tecnologies energètiques. Aquest canvi tecnològic a gran escala necessita molt de temps i molts diners, unes grans inversions que difícilment es faran en temps de crisi. Això explica per què cal esperar canvis en el nostre estil de vida i en la manera com produïm $i$ consumim béns i serveis

Hi ha també una altra raó per la que cal canviar: les tecnologies alternatives donen millors resultats si produeixen energia per consumir-la localment (quan i on es troba disponible). Si tractem d'utilitzar energies alternatives com si fossin les fòssils (per mantenir un enorme sistema de distribució centralitzat) estem en risc de matar la seva viabilitat. Hem de canviar els nostres processos de producció i consum per tal de ser capaços d'utilitzar les energies alternatives

Tot plegat és un gran repte per a tothom. Si els anys 60 a Europa es gastava la meitat d'energia per cap que ara i no érem més infeliços, vol dir que no ha de ser cap drama gastar menys energia, una energia obtinguda cada vegada més de fonts renovables. Estalviar energia passa per un canvi en el nostre estil de vida i d'una racionalització del seu ús. És essencial, però, de començar a fer-ho tan aviat com sigui possible.

Podem triar la pastilla blava i fer veure que no ens adonem del que està passant, però després inevitablement toparem amb les conseqüències. No hi ha cap més opció que ser valents i raonables i afrontar de cara el problema energètic i les seves possibles solucions.

Ens hi juguem molt.

\section{Referències}

Bardi, Ugo (2011). The limits to growth revisited. Springer.

Giampietro, M., Mayumi, K. and Sorman, A. H. 2011. The Metabolic Pattern of Societies: Where Economists Fall Short, Roultedge, London.

Meadows et al. (1972) The limits to growth: a report for the club of Rome's project on the predicament of mankind New York: Universe Books.

Murray, J., King, D. (2012) Oil's tipping point has passed. Nature, 481, (26 de gener) p. 433-435. 